\title{
Circulating and imaging markers for angiogenesis
}

\author{
Arvind P. Pathak ${ }^{1}$, Warren E. Hochfeld ${ }^{2}$, Simon L. Goodman ${ }^{3}$ and \\ Michael S. Pepper ${ }^{2,4}$
}

(1) JHU ICMIC Program, The Russell H. Morgan Department of Radiology and Radiological Science and Department of Oncology, The Johns Hopkins University School of Medicine, Baltimore, MD, USA

(2) Department of Immunology, Faculty of Health Sciences, University of Pretoria, Pretoria, South Africa

(3) Therapeutic Area Oncology - Preclinical Research, Merck KGaA, Frankfurterstr. 250, Darmstadt, Germany

(4) Département de Médecine Génétique et Développement, University Medical Center, Geneva, Switzerland

Arvind P. Pathak

Email:pathak@mri.jhu.edu

\section{Abstract}

Abundant preclinical and indirect clinical data have for several decades convincingly supported the notion that anti-angiogenesis is an effective strategy for the inhibition of tumor growth. The recent success achieved in patients with metastatic colon carcinoma using a neutralizing antibody directed against vascular endothelial growth factor (VEGF) has translated preclinical optimism into a clinical reality. With this transformation in the field of angiogenesis has come a need for reliable surrogate markers. A surrogate marker by definition serves as a substitute for the underlying process in question, and in the case of angiogenesis, microvessel density (usually in so-called "hot-spots") has until now been the most widely used parameter. However, this parameter is more akin to a static "snapshot" and does not lend itself either to the dynamic in situ assessment of the status of the tumor microvasculature or to the molecular factors that regulate its growth and involution. This has led to an acute need for developing circulating and imaging markers of angiogenesis that can be monitored in vivo at repeated intervals in large number of patients with a variety of tumors in a non-invasive manner. Such markers of angiogenesis are the subject of this review. 


\section{Introduction}

A comprehensive understanding of the molecular mechanisms that regulate angiogenesis has resulted in the design of new and more effective therapeutic strategies. Over the past few decades, a large number of angiogenesis inhibitors have been identified [1] many of which are currently being tested in clinical trials $[2,3]$. For example, a vascular endothelial growth factor (VEGF)-specific neutralizing antibody bevacizumab (Avastin) has been added to conventional therapy for colon, rectal, lung, and breast cancer patients $[4,5]$ as have kinase inhibitors, sunitinib malate (Sutent) and sorafenib (Nexavar) [5]. However, there is at present no reliable means to monitor the effects of such regimens on the angiogenic process per se. It has therefore become imperative to identify surrogate markers for angiogenesis for the following reasons:

1. To direct the dosing and scheduling of an anti-angiogenic therapeutic agent based on parameters (markers) that indicate maximal effect and minimal toxicity, rather than on maximum tolerated dose.

2. To define the optimal biological dosage of anti-angiogenic drugs.

3. To provide an early measurable sign of tumor relapse/recurrence.

4. To stratify patients according to their needs/regimens.

5. To define the best combinatory drug regime (i.e., anti-angiogenic drug plus chemo- or radio-therapy).

6. To facilitate preliminary testing of potential new therapeutic agents

It has also been pointed out that the elimination of an entire tumor vascular network could reduce the efficacy of pharmacotherapy by preventing the access of cytotoxic drugs to the tumor cells [6]. Thus the aim of an optimal anti-angiogenic regimen could be to "normalize" the structure and function of tumor vessels to allow maximal delivery of cytotoxic drugs [7], while at the same time preventing further angiogenesis. The identification, and above all, the validation of surrogate markers will help to achieve this objective.

"Classical" tumor markers include alpha-fetoprotein (AFP) for hepatocellular carcinoma and germ cell tumors, carcinoembryonic antigen (CEA) for gastrointestinal tumors, lung cancers and some breast cancers, prostate specific antigen (PSA) for benign and malignant prostate cancer, human chorionic gonadotropin (HCG) for trophoblastic tumors, calcitonin for medullary carcinoma of the thyroid, acidic prostatic phosphatases for metastatic bone disease, lactate-dehydrogenase (LDH) for lymphoma, testis cancer and pulmonary metastases, neuron specific enolase (NSE) for small cell lung cancer, and various specific tumor antigens, e.g., Ca-15.3 (adenocarcinoma of the breast, ovary and lung) and Ca-125 (ovarian carcinoma). These markers are tumor-specific and may have a place in measuring the efficacy of anti-angiogenic therapy. However, they are not 
surrogate markers of angiogenesis itself, and would thus have limited value in assessing specific inhibitory effects of this process.

To date, assessment of tumor vascularity has relied principally on counting the number of immunohistochemically identifiable microvessels in vascular hot spots in tumors [8] i.e., determining microvessel density (MVD). However, it has been demonstrated that changes in vessel diameter and MVD vary with tumor type and stage [9]. Also, Maniotis et al. [10] have demonstrated a novel process by which tumors may develop a wellstructured microcirculation, which does not include the participation of endothelial cells and is independent of angiogenesis, the so-called "vasculogenic mimicry". In such cases, the common approach of staining endothelial cells for assessing the MVD would not provide an adequate indication of angiogenesis. Although the prognostic importance of MVD in breast cancer has been well established with results indicating a correlation between areas of most intense neovascularization and metastasis [11], studies in other cancers have found no, or sometimes even negative correlations between MVD and metastasis $[12,13]$. Additionally, research has shown that the metabolic needs of cancer cells vary with the tissue of origin and change with tumor progression [14]. Thus, the number of tumor cells that can be supported by a vessel varies, and this in turn influences the vascular density of the tumor. Despite their often considerable angiogenic activity, certain human tumors can exhibit lower microvessel densities than the corresponding normal tissues [15]. Also, MVD following anti-angiogenic therapy is determined by the time-dependent ratio of capillary to tumor cell dropout, which in turn could result in increased, decreased or unchanged values of MVD [16]. Given these results, it is questionable whether MVD is the most appropriate method by which angiogenesis should be calibrated, particularly once therapy has been commenced. All of this points to the fact that non-invasive methods of evaluation may be more appropriate for the management and planning of anti-angiogenic therapy. Another source of inconsistency has been the differences in methodology for assessing MVD, i.e., different counting techniques, selection of microvessels, etc. [17]. Finally, it is not clinically feasible to regularly obtain MVD samples invasively from the patient throughout his/her treatment. Since the MVD technique relies on the availability of tissue specimens, it cannot be used for repeated measurements of the dynamic processes of vessel growth and involution in vivo [18].

Another commonly employed surrogate for angiogenesis and anti-angiogenic therapy is tumor volume. However, tumor volume changes are not consistent markers of angiogenic changes, with one study showing that the overt inhibition of angiogenesis in two human tumors was detectable before measurable effects on the tumor volume, while in another, although the tumor was responding well to treatment, its volume continued to increase $[19,20]$. Finally, anti-angiogenic therapy might not necessarily result in tumor regression but might stabilize the tumor or return it to a dormant state.

The use of circulating and imaging markers of angiogenesis overcomes many of the limitations associated with the measurement of MVD and tumor volume and seems more amenable to characterizing angiogenesis in cancer patients. Circulating markers can either be soluble or cellular in nature, and can be measured at any stage of treatment. The 
assessment of circulating concentrations of angiogenic factors such as VEGF (vascular endothelial growth factor), an important mediator of normal and tumoral angiogenesis, in conjunction with the promising preclinical results obtained by blocking VEGF or its receptors, indicates that it may be a leading candidate in the hierarchy of circulating angiogenic markers [5]. Circulating blood platelets contain many factors with the potential to be angiogenic markers including VEGFs and other cytokines. Although plasma could provide an accurate indication of circulating levels of such markers, release of endogenous VEGF from platelets needs to be prevented to avoid false positives. Rapid progress in proteomic and genomic technologies also promises to redefine this field. In vivo vascular imaging provides quantitative assessments of vessel density and blood volume fraction, and is even able to measure blood flow, oxygenation, metabolic activity and vascular permeability $[21,22]$. Current research is not only aimed at improving the resolution of these in vivo techniques, since their capacity to resolve individual microvessels (including angiogenic vessels) is limited, but also at expanding their ability to assess other functional parameters related to angiogenesis [23].

\section{Circulating markers of angiogenesis}

The potential for soluble circulating protein markers to provide an indirect measure of tumor angiogenesis has been investigated in some detail. Soluble circulating molecules have been used as prognostic as well as surrogate markers.

\section{Angiogenic growth factors and their receptors}

Both VEGF and fibroblast growth factor-2 (FGF-2) play key roles in tumor angiogenesis [24]. They are produced by tumor as well as stromal cells, and hypoxia is a potent stimulator of VEGF transcription mediated by HIF-1 $\alpha$ [25]. These growth factors are often sequestered in the extracellular matrix, and are liberated by extracellular proteolytic activity in the tumor microenvironment. Moreover, since their biological effects are dependent on binding to, activation of, and internalization by cell surface (tyrosine kinase) receptors, only growth factors capable of being receptor bound are of biological relevance [26]. In fact, total immunoreactive VEGF within node-negative breast tumors may have little value as a prognostic marker [27, 28]. Circulating levels of many angiogenic factors therefore depend on a variety of factors, including perfusion, protease activity and the hypoxic status of the tumor. To date, no clear correlation has emerged between circulating and receptor bound levels of VEGF and other angiogenic factors. A large number of studies have demonstrated a strong association between elevated expression of VEGF by primary tumors and advanced disease or poor prognosis (including lymph node metastasis) in a variety of cancers [18, 29-31]. Protein and mRNA have been measured in tumor samples, and protein has also been measured in the circulation. Circulating VEGF is generally predictive of tumor status and prognosis (e.g., see [32]), although there are important exceptions. Circulating VEGF has also been used to monitor the response to anticancer therapies and in follow-up surveillance for tumor relapse [29]. However, the data are generally tumor- and stage-specific (i.e., the findings cannot be applied across a wide spectrum of tumors), and there is a large degree of variability between studies on the same tumor type. The routine clinical use of plasma VEGF as a diagnostic, prognostic or surrogate marker has not yet been accepted. 
There are reports supporting the prognostic value of other circulating angiogenic factors such as FGF-2, hepatocyte growth factor, platelet-derived endothelial cell growth factor, transforming growth factor-beta and angiogenin, but their clinical significance is less conclusive because of limited data $[18,29,33]$.

Soluble VEGFR-1 may serve as a biomarker for angiogenesis-associated diseases including cancer. For example, it has been detected in sera from patients with colorectal and breast cancer, but not in healthy individuals [34]. Recently, the identification of a soluble form of VEGFR-2 has been reported [35]. Whether it may serve as a biomarker for angiogenesis remains to be determined.

VEGF and its receptors are clearly prime candidates in anti-cancer therapies targeting angiogenesis. A recent study has demonstrated that circulating plasma VEGF is increased in both normal and human tumor-bearing mice following therapy with a blocking antiVEGFR-2 antibody [36]. In the latter, both human and murine VEGF were increased. The mechanism may involve displacement of VEGF from VEGFR-2 by the antibody, although this remains to be demonstrated. However, VEGF was not elevated in mice treated with a soluble low-molecular weight VEGFR tyrosine kinase inhibitor. These studies demonstrate the potential of VEGF as a surrogate marker for receptor-blocking antibodies, and highlight the likelihood that because of unpredictable biological effects, each anti-angiogenic therapy will require specific markers.

\section{Cell adhesion and extracellular matrix molecules}

A variety of soluble forms of other molecules involved in the angiogenic process, namely adhesion molecules, extracellular matrix (ECM) components, proteases and protease inhibitors, have been measured in the sera and plasma of cancer patients. These include but are not limited to E-selectin, vascular cell adhesion molecule-1 (VCAM-1), endoglin/CD105, thrombospondin (TSP) and matrix metalloproteinase (MMP)-9 [18, 37]. While the prognostic potential of some of these molecules has been reported, their use as surrogate markers still remains to be established. For example, serum VCAM-1 is closely correlated with microvessel density in breast cancer [38], and higher levels were seen in women with lymph node-positive high grade than node-negative low grade tumors. As a second example, it was recently shown that low-dose metronomic chemotherapy increases plasma levels of the endogenous angiogenesis inhibitor TSP-1, in human tumor-bearing mice [39].

\section{Circulating endothelial cells and their precursors}

Putative endothelial progenitor cells (EPCs) were first identified in peripheral blood by Asahara et al. in 1997 [40]. Although extensive work has gone into validating and extending these findings, controversy still exists as to the nature and role of these cells in the angiogenic process. The blood concentrations of circulating endothelial cells (CECs) and EPCs are elevated in cancer patients [41] and have been explored as biomarkers for the efficacy of antiangiogenic treatments of cancer [6, 42-46]. However, these populations are likely heterogeneous and may potentially be of different origin (e.g., shed by tumor endothelium or mobilized from the bone marrow) [42]. Thus, phenotypic characterization of these blood-circulating cells in cancer patients is warranted before 
their use as biomarkers. While serial analysis of gene expression in endothelial cells derived from blood vessels of normal and malignant colorectal tissues and in vitro characterization of endothelial cells expanded from human blood has established that CD146 is a reliable endothelial marker [47-50], other in vitro studies and more recent in vivo data have questioned its specificity for CECs [48, 51-53]. Whereas CD146 expression may become detectable on cultured endothelial cells in the setting of ex vivo colony formation assays [49], it does not define bona fide endothelial or progenitor cells in primary blood samples from cancer patients. Characterizing the molecular profile of the putative EPC and specifically identifying determinants that distinguish it from CEC has been and remains a major challenge. Given this phenotypic variation for circulating versus tissue endothelial cells (Table 1) and the lack of specificity of CD146 expression, until a highly specific marker is discovered and validated, the quantitative evaluation of CECs or EPCs in the blood of cancer patients should be analyzed in conjunction with hematopoietic markers. Characterizing the phenotype of CECs and progenitor cell populations of interest as well as improving the analysis methodology are crucial for the clinical development and optimal use of such emerging biomarkers.

Table 1 Phenotypic analysis of putative EPCs, surface marker expression (adapted from [134])

\begin{tabular}{|l|l|l|}
\hline Surface marker & $\begin{array}{l}\text { Putative endothelial progenitor } \\
\text { cell (EPC) }\end{array}$ & $\begin{array}{l}\text { Circulating endothelium cell } \\
\text { (CEC) }\end{array}$ \\
\hline $\begin{array}{l}\text { VEGF-R2 (Flk- } \\
\text { 1/KDR) }\end{array}$ & + & + \\
\hline VEGF-R3 & + & \\
\hline VEGF-R1 (Flt-1) & & + \\
\hline FGFR1 & + & + \\
\hline Tie-2 & + & + \\
\hline $\begin{array}{l}\text { VE-Cadherin } \\
\text { (CD144) }\end{array}$ & + & + \\
\hline E-Selectin & + - & + \\
\hline CD34 & & - \\
\hline AcLDL uptake & & + \\
\hline CD31 (PECAM-1) & & \\
\hline AC133 & + & + \\
\hline Sca-1 & + & + \\
\hline cKit & + & + \\
\hline CD13 & \\
\hline vWF & \\
\hline CXCR-4 & & + \\
\hline
\end{tabular}

' + ' indicates that expression is present. ' - ' indicates that there is no expression. A blank space indicates that expression of that particular epitope has not yet been documented $v W F$ von Willebrand Factor; Sca-1 stem cell antigen-1; CXCR-4 chemokine receptor-4 


\section{Alternative approaches for identifying novel angiogenic surrogates}

In the approaches described thus far, classical knowledge of angiogenic factors has been translated into clinical assays. New technologies, including genomics and proteomics, are opening up novel analytical windows in the search for markers of angiogenesis. While classical technologies depend on the detection of pre-defined target molecules, the new technologies are more holistic, and may be able to identify surrogate patterns of gene, protein or metabolite expression indicative of an angiogenic state.

For example, DNA levels are elevated in the circulation of cancer patients [54-57], and Swisher et al. (e.g. p. 53) [58] have shown that this DNA can bear tumor specific markers. The tumor vasculature regulates circulatory access to its microenvironment, and the functionality of this vasculature is determined by its angiogenic status, that may be modulated by anti-angiogenic therapies. Along these lines, quantitative PCR has been employed to estimate the levels of circulating DNA in patients with cancer [57], which may exhibit potential as a surrogate for angiogenic status, although this has to date not been directly examined. Not only the quantity, but also the nature of free DNA might reflect the angiogenic status of a tumor, which may in future be amenable to analysis by DNA microarray technology.

Circulating leukocytes interact with and may be directly modulated by either the tumor microenvironment or via circulating cytokines and growth factors that accompany tumor progression. It is conceivable that the transcriptional activity of such modulated leukocytes may also exhibit potential as an angiogenic surrogate.

Broad spectrum investigations of protein expression patterns ("proteomics") have been employed to analyze the polypeptide content of plasma and serum in cancer patients at high resolution [59-64]. Angiogenic responses in model systems have been demonstrated to generate novel circulating proteins [65-68]. But, as has been noted elsewhere, the challenges associated with quantitation and validation of such approaches against the angiogenic status of each individual patient remain significant $[69,70]$. The validation problem for nucleic acids is exacerbated because many of the necessary technologies depend on non-linear amplification of nucleic acid molecules. While these approaches are still in their infancy, such problems may eventually be resolved.

In addition to these methods, enhanced standard technologies may also be valuable for identifying angiogenic surrogates. One example is the Luminex technique, in principle a miniaturized ELISA, but one which allows the quantitation of hundreds of proteins in microlitres of body fluid [71-73]. In addition to quantifying levels of the usual suspects, VEGFs, FGFs, IL8, etc., expression signatures identified using computational techniques may yield novel surrogate markers of angiogenesis $[74,75]$. As with most surrogates, validation in well defined pre-clinical models is indispensable, with subsequent substantiation within the clinical angiogenic context.

\section{Imaging markers of angiogenesis}

Since angiogenesis is a dynamic process, a technique for probing neovascularization in vivo without perturbing the tumor or its microenvironment would be highly appropriate 
for investigating the spatio-temporal relationships that exist between angiogenesis, tumor growth and metastasis. Any such non-invasive methods for monitoring the angiogenic status of solid tumors would be useful in the clinic for monitoring the efficacy of antiangiogenic or anti-vascular therapies, for assessing the effects of hormonal therapy on vascularization or for determining the clinical grade of the lesion. A wide array of noninvasive imaging modalities have been used to image angiogenesis. These include X-ray computed tomography (CT), magnetic resonance imaging (MRI), positron emission tomography (PET), single-photon emission computed tomography (SPECT), ultrasound, and near-infrared optical imaging, each with its own distinct potential as a tool in the non-invasive, in vivo assessment of tumor angiogenesis. What follows is a brief description of applications of these modalities to assess angiogenesis, with MRI as the focal point.

\section{Magnetic resonance imaging}

The assortment of available MRI contrast mechanisms in conjunction with its exceptional dynamic functional range, make MRI highly efficacious for assessing tumor angiogenesis in vivo. There are two broad classes of contrast mechanisms that can be employed for imaging tumor angiogenesis with MRI: endogenous and exogenous (Fig. 1). Endogenous or intrinsic contrast mechanisms are those in which the contrast arises from a naturally occurring substance in the body that has sufficient magnetic susceptibility to influence the MR signal, e.g., deoxyhemoglobin. Probing the tumor vasculature using the "endogenous contrast agent" deoxyhemoglobin present in the tumor microvessels is based on the blood oxygenation level dependent or BOLD contrast mechanism first described by Ogawa et al. [76]. The concentration of paramagnetic deoxyhemoglobin is the primary determinant of the eventual image contrast observed. The presence of deoxyhemoglobin in a blood vessel produces a difference in magnetic susceptibility between the vessel and the surrounding tissue. Such susceptibility differences induce heterogeneities in the magnetic field, on a microscopic scale, that induce dephasing of the MRI signal, leading to a reduction in the value of $\mathrm{T} 2 *$. In a T2*-weighted imaging experiment, the presence of deoxyhemoglobin in the blood vessels will produce negative contrast, i.e., darkening in voxels containing vessels. Since oxyhemoglobin is diamagnetic and does not produce the same dephasing as does deoxyhemoglobin, changes in the oxygenation status of the blood can be observed as signal changes in $\mathrm{T} 2$ * $_{\text {- }}$ weighted images. Such an approach was used to detect changes in tumor oxygenation and hence vascularization following induction of angiogenesis by angiogenic agents [77] and for obtaining maps of the "functional" vasculature in models using genetically modified animals [78]. While mainly dependent on the concentration of deoxyhemoglobin in the blood, other physiological parameters such as hematocrit, oxygen saturation, blood flow, blood volume, vessel orientation and geometry [79, 80] can all affect BOLD contrast. Yet another endogenous contrast MRI technique known as arterial spin labeling (ASL) was recently used to map the blood flow in tumors [81]. In this approach, water protons in the arterial blood pool serve as a perfusion indicator and initial studies in animal tumor models strongly supported the use of ASL as a valid approach for monitoring the effects of agents designed to change tumor perfusion. More recently, in a preliminary patient study, the use of ASL in conjunction with dynamic susceptibility-based contrast MRI for 
measuring relative regional cerebral blood flow changes in brain metastases after stereotactic radiosurgery was found to be predictive of treatment outcome [82].

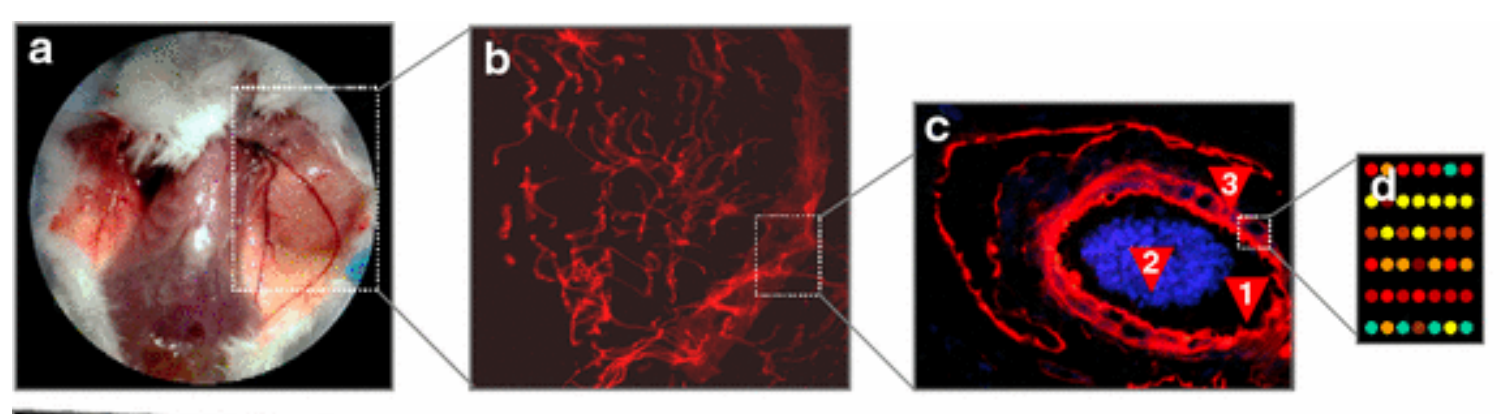

Fig. 1 Schematic illustration of the different phenomenological scales at which angiogenesis can be assessed and angiogenesis-related data acquired for eventual development into successful circulating or imaging markers. a The animal or organ level: dissection view of an MDA-MB-231 breast cancer xenograft-bearing mouse; $\mathbf{b}$ the "microcirculatory" or systemic level: z-projected image obtained from thick $(100 \mu \mathrm{m})$ section fluorescent microscopy of a tissue section from a MCF-7 breast-cancer xenograft stained with the isolectin BS-I-B4 conjugated to TRITC; $\mathbf{c}$ the level of individual microvessels and endothelial cells: fluorescent microscopy image of an arteriole from an MDA-MB-231 breast cancer xenograft tissue section stained with the same isolectin with autofluorescing erythrocytes visible in the blue channel; and culminating in $\mathbf{d}$ the molecular level: cartoon illustration of "microarray" analyses possible at the receptor or protein level. Also indicated in $\mathbf{c}$ are the three primary types of contrast mechanisms employed for imaging tumor angiogenesis (all images from Pathak and Bhujwalla, unpublished data)

Endogenous contrast MRI has the advantage of being completely non-invasive, i.e., the measurement can be conducted repeatedly in the same patient without requiring any invasive procedure including the injection of contrast agent. However, while being capable of providing maps of relative changes in various physiological parameters with good spatio-temporal resolution, endogenous contrast methods do not provide absolute quantitative measures of angiogenic parameters such as the vascular-volume-fraction of the tumor, or vascular permeability. This implies that one must therefore resort to exogenous contrast MRI techniques for quantitation.

Exogenous or extrinsic contrast mechanisms arise from agents that alter the local magnetic field in the tissue of interest when administered to the subject, thereby enhancing the contrast in MRI. Unlike the radiolabeled tracers or chemical agents used in nuclear medicine or X-ray CT that are visualized directly on the image, MR contrast agents are visualized indirectly due to the changes they induce in water proton relaxation. 
The most commonly employed MR contrast agents are paramagnetic gadolinium (Gd) chelates [83]. The seven unpaired electrons of gadolinium produce large magnetic moments that shorten both the spin-lattice relaxation time $\left(T_{1}\right)$ and spin-spin relaxation time $\left(T_{2}\right)$ of tissue water. On a $T_{1}$-weighted MRI, tissues that take up the contrast agent are positively enhanced or brightened, while the observed contrast is reversed on $T_{2}$ - or $\mathrm{T}_{2}{ }^{*}$-weighted scans. Tracer kinetic principles are then employed to calculate the tissue concentration of the contrast agent from the MR signal intensity. The various Gd complexes in use can broadly be classified as either being low molecular weight $(\mathrm{MW} \approx 0.57 \mathrm{kDa}$ ) agents, or macromolecular ( $\mathrm{MW} \approx 65 \mathrm{kDa}$ ) agents such as albumin(Gd-DTPA) compounds that reside in the intravascular space for several hours. The low MW agents are the only MR contrast agents approved for routine clinical use by the FDA. Such agents have been used to image a wide array of tumors ranging from brain to uterine tumors. However, in addition to tumor delineation, several functional or angiogenesis-relevant parameters can also be determined using these agents. However, these " $\mathrm{T}_{1}$-weighted" contrast methods involve the analyses of contrast agent-induced relaxivity changes to determine compartmental transfer constants as well as the extracellular extravascular volume fraction based on one of several theoretical compartmental models [84]. These approaches have resulted in the derivation of a wide range of clinically relevant angiogenesis-related parameters (see [22] for a detailed

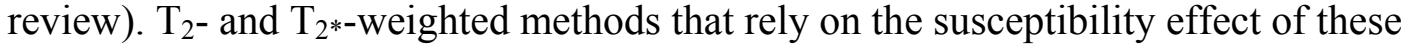
contrast agents have also been employed in the study of tumor angiogenesis. In addition to the traditional tumor blood volume measurements by both $\mathrm{T}_{1}[85]$ and $\mathrm{T}_{2}$ [86], techniques that measure tumor vessel caliber $[87,88]$, act as surrogates of tumor grade [89, 90] (Fig. 2), predict delivery of chemotherapeutic agents to the tumor interstitium [91], and aid in assessment of the efficacy of anti-angiogenic therapies [92] (Fig. 3) have been added to the accouterment of available probes. Development of techniques for correcting the effects of contrast agent extravasation via the hyper-permeable tumor vasculature [86], and the development of stereologic validation techniques for MRI approaches [93], may herald a more widespread use of MRI in the clinical assessment and management of tumor angiogenesis.
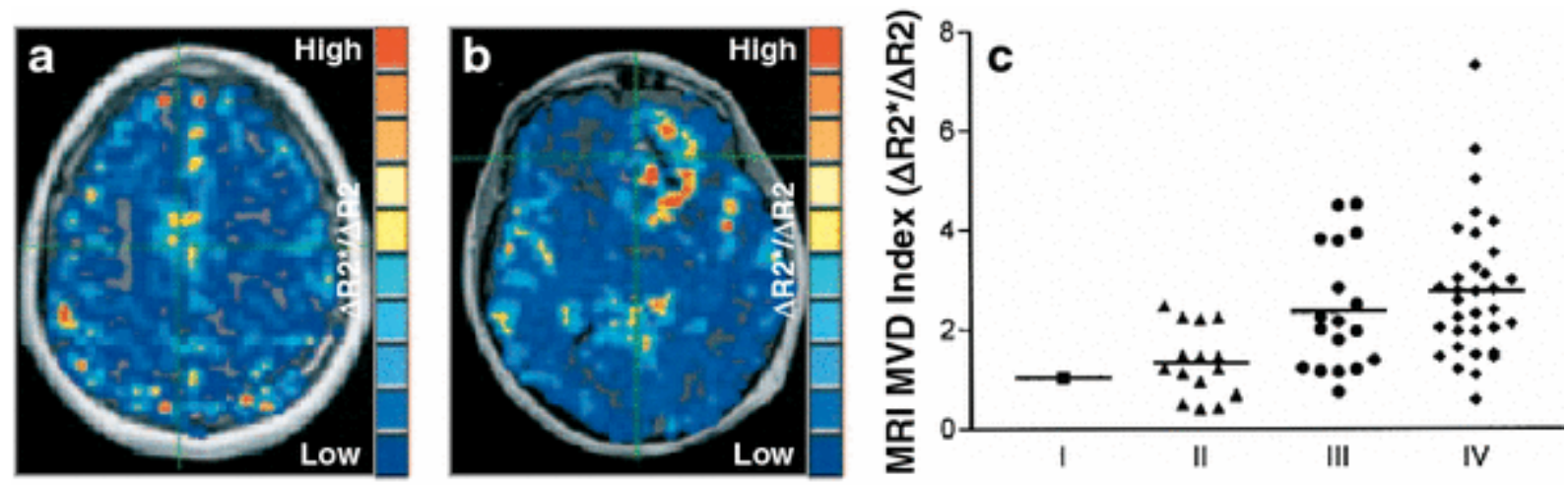

WHO Brain Tumor Grade

Fig. 2 Representative maps of the $\Delta R^{2 *} / \Delta R^{2}$ ratio, an index of MVD obtained using contrast enhanced MRI of $\mathbf{a}$ a patient with an anaplastic oligodendroglioma, and $\mathbf{b}$ a patient with glioblastoma multiforme. $\mathbf{c}$ There was a significant $(P=0.0001, r \mathrm{~S}=0.46)$ correlation between the MVD $(\Delta \mathrm{R} 2 * / \Delta \mathrm{R} 2)$ measured with MRI and tumor grade for a 
cohort of 67 patients, demonstrating the ability of MRI to track tumor MVD and grade, both non-invasively and in vivo (adapted from [90] with kind permission of the American Journal of Neuroradiology)

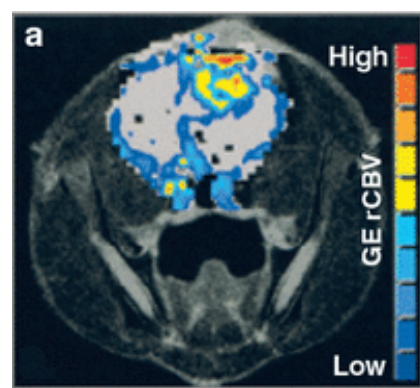

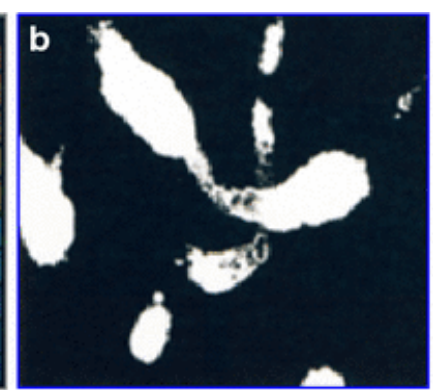

Pre anti-angiogenic Tx
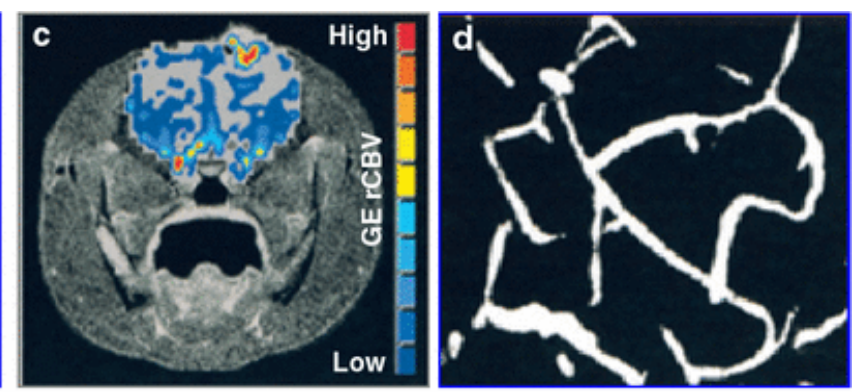

Post anti-angiogenic Tx

Fig. 3 Gradient-echo (GE) relative cerebral blood volume maps (rCBV) obtained using contrast enhanced MRI of a pre-clinical 9L gliosarcoma rat model. a Pre-treatment GE rCBV map with $\mathbf{b}$ the accompanying histology of Microfilled ${ }^{\circledR}$ vessels $(20 \times)$ illustrating the dilated and sinusoidal tumor vasculature. $\mathbf{c}$ GE rCBV map and $\mathbf{d}$ corresponding histology after treatment with the anti-angiogenic agent dexamethasone, demonstrating not only a reduction in the post-treatment GE rCBV but "normalization" of the blood vessel caliber within the tumor xenograft (adapted from [92] with kind permission of Springer Science and Business Media)

The availability of high MW contrast agents with long blood half-life times such as Albumin-Gd-DTPA complexes or polylysine-Gd-DTPA and gadomer-17, enable the quantification of parameters such as the tumor's vascular volume and the permeability surface area (PS) product while circumventing the primary disadvantage of low MW agents, namely their rapid extravasations from leaky tumor vessels. Under the assumption of water being in the fast exchange regime between all the tumor compartments, the concentration of the high MW contrast agent within a voxel is proportional to the changes in relaxation rate $\left(1 / T_{1}\right)$ before and after administration of the contrast agent. Relaxation rates can then be computed directly using either dynamic [94], or steady-state $T_{1}$ MRI [95] and spatial maps of tumor vascular volume and PS constructed after fitting to the appropriate kinetic model. Assuming negligible reflux of the contrast agent and constant blood concentrations of the agent for the duration of the MR experiment, the contrast agent uptake within the tissue of interest can be modeled as a linear function of time. In this case, the slope of the concentration-time curve is proportional to the PS and the yintercept, the vascular volume [96].

Quantification of each of these parameters requires normalization to changes in relaxation rate of the blood, which can be obtained separately from blood samples taken before administration of the contrast agent and again at the end of the MR experiment. The various models of contrast agent uptake are reviewed in [84]. Finally, it should be kept in mind that the accuracy of tissue vascular volume measurements depends not only 
on factors such as compartmentalization of the contrast agent and the rate of water exchange between the vascular and extracellular compartments [97], but also on factors such as the inflow of unsaturated spins and the type of imaging technique employed [98]. The use of high MW contrast agents has been successfully employed to assess the efficacy of anti-angiogenic therapy $[99,100]$ and to characterize differences in angiogenesis between metastatic and non-metastatic breast and prostrate cancer xenografts as well as to study the role of the functional tumor vasculature in metastasis [101].

\section{Molecular MR imaging of tumor angiogenesis}

While exogenous contrast agents enable us to probe various angiogenesis-related parameters and improve the contrast to noise ratio when performing MRI, the visualization of key receptors and molecular pathways fundamental to angiogenesis using MRI was not possible until very recently. This was primarily due to the low sensitivity of MRI compared to modalities such as PET and optical imaging for imaging pico- or nanomolar target concentrations, and other factors such as contrast agent delivery to the molecular target as well as dilution of the label within the blood pool. However, the design of novel strategies for receptor target amplification finally circumvented some of these issues making molecular MR imaging of sparse biomarkers at nanomolar or even picomolar concentrations possible [22]. These targeted contrast agents have included the use of conjugates of low molecular weight Gd-DTPA, protein carriers, dendrimers, iron oxide nanoparticles and liposomes [102]. An example of a high-relaxivity targeted contrast agent for molecular MRI of tumor angiogenesis is liquid perfluorocarbon nanoparticle emulsions that can carry several gadolinium atoms per particle [103]. An additional advantage of these perfluorocarbon constructs is that they are highly flexible and can be used as multimodal contrast agents [104].

Other novel studies have ranged from imaging inducible E-Selectin expression in human endothelial cell culture using cross-linked iron oxide nanoparticles (CLIO) covalently bound to high-affinity anti-human E-selectin $\mathrm{F}\left(\mathrm{ab}^{\prime}\right)$ fragments [105], to the detection of tumor angiogenesis in vivo by integrin $\alpha_{V} \beta_{3}$-targeted MRI, in which the targeted MR contrast agent was composed of Gd-labeled polymerized liposomes conjugated with biotinylated antibodies targeted against the $\alpha_{\mathrm{V}} \beta_{3}$ integrin, that is commonly found on tumor endothelial cell surfaces [106]. Although originally developed for applications such as measuring ICAM-1 expression in autoimmune encephalitis [107], or for imaging fibrin-rich clots in an animal model of human thrombus formation [108], these novel molecular imaging approaches could be extended or adapted to image the same or similar targets in an "angiogenic" milieu. The use of targeted contrast agents in conjunction with the functional imaging techniques described earlier has begun to provide unique opportunities for understanding receptor-mediated pathways in tumor angiogenesis using MRI.

\section{Imaging tumor angiogenesis with complementary imaging modalities}

In addition to MRI, several techniques for imaging tumor angiogenesis have been developed using other imaging modalities ([109] reviews some of these). Both PET and SPECT imaging are quantitative techniques that are sensitive to very low concentrations 
of tracer molecules. PET, which is capable of detecting picomolar concentrations of tracer, is $\sim$ ten times more sensitive than SPECT. Both methods are well suited to molecular imaging because of the generally low concentrations of target molecules, as well as for gathering hemodynamic data. However, because the radionuclides used in PET tracers have a very short half-life $\left(2 \min\right.$ for ${ }^{15} \mathrm{O}, 10 \mathrm{~min}$ for ${ }^{13} \mathrm{~N}, 20 \mathrm{~min}$ for ${ }^{11} \mathrm{C}$, and 110 min for ${ }^{18} \mathrm{~F}$ ), PET studies are usually performed at facilities with a PET scanner and the necessary cyclotron and chemical synthesis laboratory for the preparation of such tracers. Radionuclides used for SPECT are easier to prepare and somewhat longer lived than those used for PET ( $6 \mathrm{~h}$ for ${ }^{99 \mathrm{~m}} \mathrm{Tc}, 67 \mathrm{~h}$ for ${ }^{111} \mathrm{In}$, and $13.2 \mathrm{~h}$ for ${ }^{123} \mathrm{I}$ ), with SPECT imaging being more widely available than PET imaging. However, both PET and SPECT images suffer from low spatial resolution compared to MRI or CT images. An innovative study using SPECT recently demonstrated the viability of imaging an antibody fragment against the ED-B splice variant of fibronectin, an angiogenic marker [110]. With this technique, the authors could distinguish between inactive and actively growing lesions in patients with lung, colorectal, or brain cancer. Advances in ultrasound imaging instrumentation and ultrasound blood-pool contrast agents have enabled the sonographic detection of tumor angiogenesis. A novel study using microbubbles targeted to $\alpha_{V}$ integrins expressed in neovessels, enabled the non-invasive assessment of angiogenesis in vivo by ultrasound [111]. More recently, the quantification of tumor vascularity was achieved using a multi-modal approach [112]. In this study, the authors employed another microbubble contrast agent and contrast enhanced sonography to quantify tumor vascularization in mice using fractal analysis. Ultrasound measurements were compared with fractional vascular volume measurements using MRI and with fluorodeoxyglucose (FDG) PET measurements, to identify the viable regions within the tumor. An excellent correlation was found between ultrasound and MRI, as well as between the ultrasound and FDG PET measurements. The high sensitivity of photon detection, widespread availability of a large range of novel fluorescent probes and targets, and the development of near-infrared techniques has made optical imaging a favored modality for imaging molecular targets. More recently, diffuse near-infrared optical spectroscopy was employed to quantify the dynamics of optical contrast agents in a rat tumor model in vivo, in conjunction with MRI [113]. The kinetics of the optical contrast agent indocyanine green and methylene blue were found to be analogous to those of a macromolecular and small-molecular-weight MR contrast agent, respectively. Conventional and quantitative microscopy techniques ranging from fluorescence and electron microscopy to confocal and multiphoton microscopy have been extensively employed to probe the morphological and functional anomalies of angiogenic tumor vessels (see [21] for an excellent review of these and complementary imaging techniques for imaging angiogenesis). Of these, high-speed intravital multiphoton laser scanning microscopy has been used successfully to obtain structural and functional images of the microvasculature, lymphatics, and of leukocyte-endothelial interactions in animal tumor models at very-high resolution, while circumventing disadvantages such as limited imaging depth and phototoxicity usually associated with traditional fluorescence microscopy [114]. Finally a special variant of multiphoton laser scanning microscopy known as second-harmonic generation imaging was recently employed to dynamically assess the modulation of collagen content in tumors in vivo [115]. The intense secondharmonic generation (SHG)-nonabsorptive frequency doubling of the excitation laser line 
produced by endogenous protein structures, forms the basis of this novel imaging approach. This in turn enables one to obtain high-resolution three-dimensional images of the tissue architecture using a laser-scanning microscope [116]. In addition to the abovementioned novel imaging techniques, the development of multimodal contrast agents, i.e., contrast agents simultaneously observable with two or more imaging modalities, allows researchers to simultaneously exploit the strengths of each imaging modality. One such study developed a contrast agent based on albumin that was triplylabeled with biotin, a fluorescent tag, and Gd-DTPA, allowing optical, plasma mass spectrometry and MRI detection of the same agent [117]. The biotin tag allowed in vivo chasing of the contrast material from the blood by intravenous administration of avidin that caused the contrast agent to disappear from the blood vessels, while that which had extravasated prior to administration of avidin was not cleared. Thus, one can modulate the rate of clearance of the contrast material from the circulation while imaging it. Although nuclear medicine techniques such as SPECT and PET tend to be limited in their spatial resolution and require the administration of radioisotopes, and light scattering in soft tissues often limits the effective depth of optical techniques, the development of multimodal probes promises to circumvent these drawbacks, by allowing us to exploit the sensitivity of these techniques, while combining them with the advantages of MRI, such as higher spatial resolution. While intravital microscopy approaches provide very high imaging resolutions and have provided crucial insights into the pathophysiology of tumors [118], such techniques are limited in terms of the tissue depth that can be probed and the range of available functional contrast mechanisms.

Also worth mentioning here is the burgeoning field of nanotechnology (i.e., devices or technologies with spatial dimensions of the order of 1-1,000 nm) and its emerging role in cancer detection and therapy. Broadly, nanotechnologies fall into two classes: the first includes the design and fabrication of "nanovectors" or "nanocarriers" for the targeted delivery of various anticancer therapeutics or contrast agents for imaging, while the second includes the precise patterning or fabrication of surfaces or devices (e.g., nanotubes and nanowires) at nanoscale resolutions (see the excellent review by Ferrari et al. [119] for details). Several investigators have used nanoparticulate contrast agents directed to $\alpha_{\mathrm{V}} \beta_{3}$-integrins to image angiogenesis in vivo using MRI $[103,106]$. As summarized by Weissleder [120], both derivatized and "smart" iron oxide nanoparticles have been employed to probe molecular pathways central to cancer with MRI and complementary imaging modalities such as optical and CT imaging. More recently, quantum dots have also been employed to image angiogenesis [121] and distinguish different aspects of the tumor micromilieu such as microvessels, from the ECM [122]. While in vivo imaging methods such as MRI are unable to match the resolution of optical techniques, they nonetheless have a wide array of contrast mechanisms that are sensitive to the angiogenic status of a tumor and are not limited in their tissue penetration. The development of high-resolution in vivo techniques in conjunction with the design of novel imaging probes and target amplification strategies promises to herald a new era in imaging angiogenesis, by eliminating the resolution disparity and enhancing the assessment of angiogenic vessel architecture and functionality. 
The studies described earlier attest to the validity and reliability of the various imaging techniques that have been used to determine vascular parameters. In fact, an elegant study by Batchelor et al. [123] using both in vivo MRI markers and circulating markers of brain tumor angiogenesis, recently demonstrated that the pan-VEGF receptor tyrosine kinase inhibitor AZD2171 normalized the tumor vasculature and alleviated edema in glioblastoma patients. While no single imaging modality is ideal in all circumstances; each has strengths and weaknesses with respect to its availability, sensitivity, ease of accurate and reproducible quantification, the regions of the body that can be imaged, the availability of compatible intravascular contrast agents, and contrast agent toxicity.

\section{Alternative approaches for identifying novel imaging markers}

As described above, targeting contrast agents to blood vessels using probes that bind specifically to "molecular zip codes" is a burgeoning area of research [124]. Exploiting the molecular heterogeneity of the tumor vasculature to simultaneously design targeted contrast agents as well as therapeutic payloads directed at the most susceptible new angiogenic vessels, is an extremely attractive option. A novel technique that has mapped much of the diversity of receptors in human blood vessels is "in vivo phage display" [125]. In vivo phage display involves screening with huge random libraries of peptides displayed as recombinant molecules on the surface of bacteriophage, to identify molecular targets to which specific phage bind [124]. This approach has enabled targeting not only of normal blood vessels [126] but also angiogenic tumor vessels [127], and more recently, the identification of tumor "stage-specific" molecular zip codes [128]. Although the physiological basis of this vascular heterogeneity is an ongoing area of investigation, phage library panning holds much promise in terms of the identification of novel markers for imaging angiogenesis dynamically and in vivo in the future.

It is worth pointing out that the retrieval and analysis of molecular components leading to the identification of novel targets necessitates robust bioinformatics systems and novel statistical tools for data mining. Peale et al. [75] have nicely summarized the evolution and contribution of gene profiling techniques over the past several decades to the study of angiogenesis and vascular development. These techniques now include sophisticated analyses with new software tools that, in conjunction with analysis of human genetic data and transgenic mouse models, have helped develop our understanding from the level of individual genes to that of entire regulatory networks [129]. In fact, the complexity of microarray data, its integration with multi-dimensional, multi-parametric imaging and/or other types of clinical data have heralded the new discipline of "systems biology", which provides a framework and methods for comprehending the interactions between these data $[129,130]$. Novel multidimensional "visualization" and "data-mining" tools such the proposed "connectivity map" will empower researchers to avoid oversimplifications and appreciate the information contained in these complex interactions [131]. These same approaches could then be employed for the identification and development of heretofore unknown markers of tumor angiogenesis. 


\section{Conclusion}

The demonstration that neutralizing anti-VEGF antibodies are efficacious in prolonging survival in metastatic colon cancer has given credence to the principle of mechanismdriven drug development [4]. This antibody has also been shown to have measurable therapeutic and biological effects in breast, renal and rectal carcinoma [45, 132, 133]. With regard to the latter, Willett et al. [45] have shown that following a single infusion of antibody, reductions are seen in tumor perfusion, vascular volume, microvascular density, interstitial fluid pressure and the number of EPCs, while vessel maturity (pericyte coverage) was increased. This confirms the usefulness of histological, circulating and imaging markers in monitoring the effects of an anti-angiogenic agent prior to the appearance of overt changes in tumor size.

As our understanding of the process of tumor blood vessel formation evolves, new markers will be identified that will be accurate measures of the angiogenic process. Exciting prospects include the use of gene arrays to provide an angiogenesis profile, from which appropriately validated markers could emerge. Biomarkers in turn could become targets for therapy as, e.g., an anti-HER2 monoclonal antibody (trastuzumab or Herceptin) and a BCR-ABL kinase inhibitor (imatinimb mesylate or Gleevec). In summary, recent clinical validation of a very large body of preclinical data points to the efficacy of anti-angiogenic therapy for the treatment of cancer. As the number of clinically validated anti-angiogenic agents increases, optimization of dose and schedule are likely to be based on levels of surrogate markers rather than on maximum tolerated dose, and this will be accompanied by a concomitant demand for non-invasive imaging techniques to assess the efficacy of such an approach in vivo.

\section{References}

1. Angiogenesis inhibitors in clinical trials 2007 Available from:

http://www.cancer.gov/clinicaltrials/developments/anti-angio-table

2. Madhusudan S, Harris AL (2002) Drug inhibition of angiogenesis. Curr Opin Pharmacol 2(4):403-414.

3. Park JW, Kerbel RS, Kelloff GJ, Barrett JC, Chabner BA, Parkinson DR, Peck J, Ruddon RW, Sigman CC, Slamon DJ (2004) Rationale for biomarkers and surrogate end points in mechanism-driven oncology drug development. Clin Cancer Res 10(11):3885-3896.

4. Hurwitz H, Fehrenbacher L, Novotny W, Cartwright T, Hainsworth J, Heim W, Berlin J, Baron A, Griffing S, Holmgren E, Ferrara N, Fyfe G, Rogers B, Ross R, Kabbinavar F (2004) Bevacizumab plus irinotecan, fluorouracil, and leucovorin for metastatic colorectal cancer. N Engl J Med 350(23):2335-2342. 
5. Crew JP (1999) Vascular endothelial growth factor: an important angiogenic mediator in bladder cancer. Eur Urol 35(1):2-8.

6. Schneider M, Tjwa M, Carmeliet P (2005) A surrogate marker to monitor angiogenesis at last. Cancer Cell 7(1):3-4

7. Jain RK (2001) Normalizing tumor vasculature with anti-angiogenic therapy: a new paradigm for combination therapy. Nat Med 7(9):987-989.

8. Fox SB, Harris AL (2004) Histological quantification of tumour angiogenesis. APMIS 112(7-8):413-430.

9. Holash P, Maisonpierre PC, Compton D, Boland P, Alexander CR, Zagzag D, Yancopoulos GD, Wiegand SJ (1999) Vessel cooption, regression, and growth in tumors mediated by angiopoietins and VEGF. Science 284:1994-1998.

10. Maniotis AJ, Folgberg R, Hess A, Seftor EA, Gardner LM, Pe'er J, Trent JM, Meltzer PS, Hendrix MJC (1999) Vascular channel formation by human melanoma cells in vivo and in vitro: vasculogenic mimicry. Am J Pathol 155(3):739-752

11. Weidner N, Semple JP, Welch WR, Folkman J (1991) Tumor angiogenesis and metastasis - correlation in invasive breast carcinoma. N Engl J Med 324(1):1-8

12. Sarbia M, Bittinger F, Porschen R, Dutkowski P, Willers R, Gabbert HE (1996) Tumor vascularization and prognosis in squamous cell carcinomas of the esophagus. Anticancer Res 15:2117-2122

13. Bossi P, Viale G, Lee AKC, Alfano RM, Coggi G, Bosari S (1995) Angiogenesis in colorectal tumors: microvessel quantitation in adenomas and carcinomas with clinicopathological correlations. Cancer Res 55:5049-5053

14. Thomlinson RH, Gray LH (1955) The histological structure of some human lung cancers and the possible implications for radiotherapy. Br J Cancer 9(4):539-549

15. Steinberg F, Rohrborn HJ, Otto T, Scheufler KM, Streffer C (1997) NIR reflection measurements of hemoglobin and cytochrome aa 3 in healthy tissues and tumors. Correlations to oxygen consumption: preclinical and clinical data. Adv Exp Med Biol 428:69-77

16. Hlatky L, Hahnfeldt P, Folkman J (2002) Clinical application of antiangiogenic 
therapy: microvessel density, what it does and doesn't tell us. J Natl Cancer Inst 94(12):883-893

17. Ellis LM, Walker RA, Gasparini G (1998) Current controversies in cancer: is determination of angiogenic activity in human clinically useful? Eur J Cancer 34(5):609-618.

18. Ruegg C, Meuwly JY, Driscoll R, Werffeli P, Zaman K, Stupp R (2003) The quest for surrogate markers of angiogenesis: a paradigm for translational research in tumor angiogenesis and anti-angiogenesis trials. Curr Mol Med 3(8):673-691.

19. Poptani H, Puumalainen AM, Grohn OI, Loimas S, Kainulainen R, Yla-Herttuala S, Kauppinen RA (1998) Monitoring thymide kinase and gancicliovir-induced changes in rat malignant glioma in vivo by NMR. Cancer Gene Ther 5(2):101-109

20. Lindner DJ, Borden EC (1997) Effects of tamoxifen and interferon-beta on tumorinduced angiogenesis. Int J Cancer 71(3):456-461. doi:10.1002/(SICI)10970215(19970502)71:3<456::AID-IJC25>3.0.CO;2-C

21. McDonald DM, Choyke PL (2003) Imaging of angiogenesis: from microscope to clinic. Nat Med 9(6):713-725.

22. Pathak AP, Gimi B, Glunde K, Ackerstaf E, Artemov D, Bhujwalla ZM (2004) Molecular and functional imaging of cancer: advances in MRI and MRS. Methods Enzymol 386:3-60

23. Pathak AP, Artemov D, Ward BD, Jackson DG, Neeman M, Bhujwalla ZM (2005) Characterizing extravascular fluid transport of macromolecules in the tumor interstitium by magnetic resonance imaging. Cancer Res 65(4):1425-1432.

24. Ferrara N, Alitalo K (1999) Clinical applications of angiogenic growth factors and their inhibitors. Nat Med 5(12):1359-1364.

25. Semenza GL (2003) Targeting HIF-1 for cancer therapy. Nat Rev Cancer 3(10):721-732.

26. Bergers $\mathrm{G}$, Brekken R, McMahon G, Vu TH, Itoh T, Tamaki K, Tanzawa K, Thorpe P, Itohara S, Werb Z, Hanahan D (2000) Matrix metalloproteinase-9 triggers the angiogenic switch during carcinogenesis. Nat Cell Biol 2(10):737-744.

27. De Paola F, Granato AM, Scarpi E, Monti F, Medri L, Bianchi S, Amadori D, Volpi 
A (2002) Vascular endothelial growth factor and prognosis in patients with nodenegative breast cancer. Int J Cancer 98(2):228-233.

28. MacConmara M, O’Hanlon DM, Kiely MJ, Connolly Y, Jeffers M, Keane FB (2002) An evaluation of the prognostic significance of vascular endothelial growth factor in node positive primary breast carcinoma. Int J Oncol 20(4):717-721

29. Poon RT, Fan ST, Wong J (2001) Clinical implications of circulating angiogenic factors in cancer patients. J Clin Oncol 19(4):1207-1225

30. Drevs J, Laus C, Medinger M, Schmidt-Gersbach C, Unger C (2002) Antiangiogenesis: current clinical data and future perspectives. Onkologie 25(6):520-527.

31. Kleespies A, Guba M, Jauch KW, Bruns CJ (2004) Vascular endothelial growth factor in esophageal cancer. J Surg Oncol 87(2):95-104.

32. Fuhrmann-Benzakein E, Ma MN, Rubbia-Brandt L, Mentha G, Ruefenacht D, Sappino AP, Pepper MS (2000) Elevated levels of angiogenic cytokines in the plasma of cancer patients. Int J Cancer 85(1):40-45. doi:10.1002/(SICI)10970215(20000101)85:1<40::AID-IJC7>3.0.CO;2-L

33. Gasparini G (2001) Clinical significance of determination of surrogate markers of angiogenesis in breast cancer. Crit Rev Oncol Hematol 37(2):97-114.

34. Kumar H, Heer K, Greenman J, Kerin MJ, Monson JR (2002) Soluble FLT-1 is detectable in the sera of colorectal and breast cancer patients. Anticancer Res 22(3):1877-1880

35. Ebos JM, Bocci G, Man S, Thorpe PE, Hicklin DJ, Zhou D, Jia X, Kerbel RS (2004) A naturally occurring soluble form of vascular endothelial growth factor receptor 2 detected in mouse and human plasma. Mol Cancer Res 2(6):315-326

36. Bocci G, Man S, Green SK, Francia G, Ebos JM, du Manoir JM, Weinerman A, Emmenegger U, Ma L, Thorpe P, Davidoff A, Huber J, Hicklin DJ, Kerbel RS (2004) Increased plasma vascular endothelial growth factor (VEGF) as a surrogate marker for optimal therapeutic dosing of VEGF receptor-2 monoclonal antibodies. Cancer Res 64(18):6616-6625.

37. Drevs J (2003) Soluble markers for the detection of hypoxia under antiangiogenic treatment. Anticancer Res 23(2A):1159-1161 
38. Byrne GJ, Bundred NJ (2000) Surrogate markers of tumoral angiogenesis. Int J Biol Markers 15(4):334-339

39. Bocci G, Francia G, Man S, Lawler J, Kerbel RS (2003) Thrombospondin 1, a mediator of the antiangiogenic effects of low-dose metronomic chemotherapy. Proc Natl Acad Sci USA 100(22):12917-12922.

40. Asahara T, Murohara T, Sullivan A, Silver M, van der Zee R, Li T, Witzenbichler B, Schatteman G, Isner JM (1997) Isolation of putative progenitor endothelial cells for angiogenesis. Science 275(5302):964-967.

41. Mancuso P, Burlini A, Pruneri G, Goldhirsch A, Martinelli G, Bertolini F (2001) Resting and activated endothelial cells are increased in the peripheral blood of cancer patients. Blood 97(11):3658-3661.

42. Beaudry P, Force J, Naumov GN, Wang A, Baker CH, Ryan A, Soker S, Johnson BE, Folkman J, Heymach JV (2005) Differential effects of vascular endothelial growth factor receptor-2 inhibitor ZD6474 on circulating endothelial progenitors and mature circulating endothelial cells: implications for use as a surrogate marker of antiangiogenic activity. Clin Cancer Res 11(9):3514-3522.

43. Monestiroli S, Mancuso P, Burlini A, Pruneri G, Dell'Agnola C, Gobbi A, Martinelli G, Bertolini F (2001) Kinetics and viability of circulating endothelial cells as surrogate angiogenesis marker in an animal model of human lymphoma. Cancer Res 61(11):4341-4344

44. Shaked Y, Bertolini F, Man S, Rogers MS, Cervi D, Foutz T, Rawn K, Voskas D, Dumont DJ, Ben-David Y, Lawler J, Henkin J, Huber J, Hicklin DJ, D’Amato RJ, Kerbel RS (2005) Genetic heterogeneity of the vasculogenic phenotype parallels angiogenesis; implications for cellular surrogate marker analysis of antiangiogenesis. Cancer Cell 7(1):101-111

45. Willett CG, Boucher Y, di Tomaso E, Duda DG, Munn LL, Tong RT, Chung DC, Sahani DV, Kalva SP, Kozin SV, Mino M, Cohen KS, Scadden DT, Hartford AC, Fischman AJ, Clark JW, Ryan DP, Zhu AX, Blaszkowsky LS, Chen HX, Shellito PC, Lauwers GY, Jain RK (2004) Direct evidence that the VEGF-specific antibody bevacizumab has antivascular effects in human rectal cancer. Nat Med 10(2):145147.

46. Willett CG, Boucher Y, Duda DG, di Tomaso E, Munn LL, Tong RT, Kozin SV, Petit L, Jain RK, Chung DC, Sahani DV, Kalva SP, Cohen KS, Scadden DT, Fischman AJ, Clark JW, Ryan DP, Zhu AX, Blaszkowsky LS, Shellito PC, MinoKenudson M, Lauwers GY (2005) Surrogate markers for antiangiogenic therapy and 
dose-limiting toxicities for bevacizumab with radiation and chemotherapy: continued experience of a phase I trial in rectal cancer patients. J Clin Oncol 23(31):8136-8139.

47. Beerepoot LV, Mehra N, Vermaat JS, Zonnenberg BA, Gebbink MF, Voest EE (2004) Increased levels of viable circulating endothelial cells are an indicator of progressive disease in cancer patients. Ann Oncol 15(1):139-145.

48. Elshal MF, Khan SS, Takahashi Y, Solomon MA, McCoy JP Jr (2005) CD146 (Mel-CAM), an adhesion marker of endothelial cells, is a novel marker of lymphocyte subset activation in normal peripheral blood. Blood 106(8):2923-2924.

49. Ingram DA, Mead LE, Tanaka H, Meade V, Fenoglio A, Mortell K, Pollok K, Ferkowicz MJ, Gilley D, Yoder MC (2004) Identification of a novel hierarchy of endothelial progenitor cells using human peripheral and umbilical cord blood. Blood 104(9):2752-2760.

50. St Croix B, Rago C, Velculescu V, Traverso G, Romans KE, Montgomery E, Lal A, Riggins GJ, Lengauer C, Vogelstein B, Kinzler KW (2000) Genes expressed in human tumor endothelium. Science 289(5482):1197-1202.

51. Filshie RJ, Zannettino AC, Makrynikola V, Gronthos S, Henniker AJ, Bendall LJ, Gottlieb DJ, Simmons PJ, Bradstock KF (1998) MUC18, a member of the immunoglobulin superfamily, is expressed on bone marrow fibroblasts and a subset of hematological malignancies. Leukemia 12(3):414-421.

52. Khan SS, Solomon MA, McCoy JP Jr (2005) Detection of circulating endothelial cells and endothelial progenitor cells by flow cytometry. Cytometry B Clin Cytom 64(1):1-8.

53. Schon M, Kahne T, Gollnick H, Schon MP (2005) Expression of gp130 in tumors and inflammatory disorders of the skin: formal proof of its identity as CD146 (MUC18, Mel-CAM). J Invest Dermatol 125(2):353-363

54. Stroun M, Anker P, Lyautey J, Lederrey C, Maurice PA (1987) Isolation and characterization of DNA from the plasma of cancer patients. Eur J Cancer Clin Oncol 23(6):707-712.

55. Taback B, Fujiwara Y, Wang HJ, Foshag LJ, Morton DL, Hoon DS (2001) Prognostic significance of circulating microsatellite markers in the plasma of melanoma patients. Cancer Res 61(15):5723-5726 
56. Taback B, Hoon DS (2004) Circulating nucleic acids and proteomics of plasma/serum: clinical utility. Ann N Y Acad Sci 1022:1-8.

57. Taback B, O’Day SJ, Hoon DS (2004) Quantification of circulating DNA in the plasma and serum of cancer patients. Ann N Y Acad Sci 1022:17-24.

58. Swisher EM, Wollan M, Mahtani SM, Willner JB, Garcia R, Goff BA, King MC (2005) Tumor-specific p53 sequences in blood and peritoneal fluid of women with epithelial ovarian cancer. Am J Obstet Gynecol 193(3 Pt 1):662-667.

59. Vlahou A, Schorge JO, Gregory BW, Coleman RL (2003) Diagnosis of ovarian cancer using decision tree classification of mass spectral data. J Biomed Biotechnol 5:308-314.

60. Xiao X, Zhao X, Liu J, Guo F, Liu D, He D (2004) Discovery of laryngeal carcinoma by serum proteomic pattern analysis. Sci China C Life Sci 47(3):219223.

61. Petricoin EF, Liotta LA (2004) Proteomic approaches in cancer risk and response assessment. Trends Mol Med 10(2):59-64.

62. Wadsworth JT, Somers KD, Cazares LH, Malik G, Adam BL, Stack BC Jr, Wright GL Jr, Semmes OJ (2004) Serum protein profiles to identify head and neck cancer. Clin Cancer Res 10(5):1625-1632.

63. Steel LF, Shumpert D, Trotter M, Seeholzer SH, Evans AA, London WT, Dwek R, Block TM (2003) A strategy for the comparative analysis of serum proteomes for the discovery of biomarkers for hepatocellular carcinoma. Proteomics 3(5):601-609.

64. Poon TC, Yip TT, Chan AT, Yip C, Yip V, Mok TS, Lee CC, Leung TW, Ho SK, Johnson PJ (2003) Comprehensive proteomic profiling identifies serum proteomic signatures for detection of hepatocellular carcinoma and its subtypes. Clin Chem 49(5):752-760.

65. Hood BL, Lucas DA, Kim G, Chan KC, Blonder J, Issaq HJ, Veenstra TD, Conrads TP, Pollet I, Karsan A (2005) Quantitative analysis of the low molecular weight serum proteome using $18 \mathrm{O}$ stable isotope labeling in a lung tumor xenograft mouse model. J Am Soc Mass Spectrom 16(8):1221-1230.

66. Koomen JM, Li D, Xiao LC, Liu TC, Coombes KR, Abbruzzese J, Kobayashi R (2005) Direct tandem mass spectrometry reveals limitations in protein profiling experiments for plasma biomarker discovery. J Proteome Res 4(3):972-981. 
67. Juan HF, Chen JH, Hsu WT, Huang SC, Chen ST, Yi-Chung Lin J, Chang YW, Chiang CY, Wen LL, Chan DC, Liu YC, Chen YJ (2004) Identification of tumorassociated plasma biomarkers using proteomic techniques: from mouse to human. Proteomics 4(9):2766-2775.

68. Thompson LJ, Wang F, Proia AD, Peters KG, Jarrold B, Greis KD (2003) Proteome analysis of the rat cornea during angiogenesis. Proteomics 3(11):2258-2266.

69. Fujii K, Nakano T, Kanazawa M, Akimoto S, Hirano T, Kato H, Nishimura T (2005) Clinical-scale high-throughput human plasma proteome analysis: lung adenocarcinoma. Proteomics 5(4):1150-1159.

70. Soltys SG, Le QT, Shi G, Tibshirani R, Giaccia AJ, Koong AC (2004) The use of plasma surface-enhanced laser desorption/ionization time-of-flight mass spectrometry proteomic patterns for detection of head and neck squamous cell cancers. Clin Cancer Res 10(14):4806-4812.

71. Pang S, Smith J, Onley D, Reeve J, Walker M, Foy C (2005) A comparability study of the emerging protein array platforms with established ELISA procedures. $\mathrm{J}$ Immunol Methods 302(1-2):1-12.

72. Liu MY, Xydakis AM, Hoogeveen RC, Jones PH, Smith EO, Nelson KW, Ballantyne CM (2005) Multiplexed analysis of biomarkers related to obesity and the metabolic syndrome in human plasma, using the Luminex-100 system. Clin Chem 51(7):1102-1109.

73. Dupont NC, Wang K, Wadhwa PD, Culhane JF, Nelson EL (2005) Validation and comparison of luminex multiplex cytokine analysis kits with ELISA: determinations of a panel of nine cytokines in clinical sample culture supernatants. J Reprod Immunol 66(2):175-191

74. Gerritsen ME, Soriano R, Yang S, Ingle G, Zlot C, Toy K, Winer J, Draksharapu A, Peale F, Wu TD, Williams PM (2002) In silico data filtering to identify new angiogenesis targets from a large in vitro gene profiling data set. Physiol Genomics 10(1):13-20

75. Peale FV Jr, Gerritsen ME (2001) Gene profiling techniques and their application in angiogenesis and vascular development. J Pathol 195(1):7-19.

76. Ogawa S (1990) MRI of blood vessels at high fields: in vivo and in vitro measurements and image simulation. Magn Reson Med 16:9-18. 
77. Abramovitch R, Frenkiel D, Neeman M (1998) Analysis of subcutaneous angiogenesis by gradient echo magnetic resonance imaging. Magn Reson Med 39(5):813-824.

78. Carmeliet P, Dor Y, Herbert J-M, Fukumura D, Brusselmans K, Dewerchin M, Neeman M, Bono F, Abramovitch R, Maxwell P, Koch CJ, Ratcliffe P, Moons L, Jain RK, Collen D, Keshet E (1998) Role of HIF-1 in hypoxia-mediated apoptosis, cell proliferation and tumor angiogenesis. Nature 394:485-490.

79. Weisskoff RM (1999) Basic theoretical models of bold signal change. In: Moonen CTW, Bandettini PA (eds) Functional MRI. Springer, Heidelberg, pp 115-125

80. Pathak AP, Rand SD, Schmainda KM (2003) The effect of brain tumor angiogenesis on the in vivo relationship between the gradient-echo relaxation rate change (DeltaR2*) and contrast agent (MION) dose. J Magn Reson Imaging 18(4):397-403.

81. Silva AC, Kim S-G, Garwood M (2000) Imaging blood flow in brain tumors using arterial spin labeling. Magn Reson Med 44:169-173. doi:10.1002/15222594(200008)44:2<169::AID-MRM1>3.0.CO;2-U

82. Weber MA, Thilmann C, Lichy MP, Gunther M, Delorme S, Zuna I, Bongers A, Schad LR, Debus J, Kauczor HU, Essig M, Schlemmer HP (2004) Assessment of irradiated brain metastases by means of arterial spin-labeling and dynamic susceptibility-weighted contrast-enhanced perfusion MRI: initial results. Invest Radiol 39(5):277-287.

83. Lauffer RB (1987) Paramagnetic metal complexes as water proton relaxation agents for nmr imaging: theory and design. Chem Rev 87:901-927.

84. Tofts PS (1997) Modeling tracer kinetics in dynamic Gd-DTPA MR imaging. J Magn Reson Imaging 7:91-101.

85. Hacklander T, Reichenbach JR, Hofer M, Modder U (1996) Measurement of cerebral blood volume via the relaxing effect low-dose gadopentetate dimeglumine during bolus transit. AJNR Am J Neuroradiol 17:821-830

86. Donahue KM, Krouwer HG, Rand SD, Pathak AP, Marszalkowski CS, Censky SC, Prost RW (2000) Utility of simultaneously acquired gradient-echo and spin-echo cerebral blood volume and morphology maps in brain tumor patients. Magn Reson Med 43(6):845-853. doi:10.1002/1522-2594(200006)43:6<845::AIDMRM10>3.0.CO;2-J 
87. Dennie J, Mandeville JB, Boxerman JL, Packard SD, Rosen BR, Weisskoff RM (1998) NMR imaging of changes in vascular morphology due to tumor angiogenesis. Magn Reson Med 40:793-799.

88. Tropres I, Grimault S, Vaeth A, Grillon E, Julien C, Payen JF, Lamalle L, Decorps M (2001) Vessel size imaging. Magn Reson Med 45(3):397-408. doi:10.1002/15222594(200103)45:3<397::AID-MRM1052>3.0.CO;2-3

89. Maeda M, Itoh S, Kimura H, Iwasaki T, Hayashi N, Yamamoto K, Ishii Y, Kubota T (1993) Tumor vascularity in the brain: evaluation with dynamic susceptibilitycontrast MR imaging. Radiology 189:233-238

90. Schmainda KM, Rand SD, Joseph AM, Lund R, Ward BD, Pathak AP, Ulmer JL, Badruddoja MA, Krouwer HG (2004) Characterization of a first-pass gradient-echo spin-echo method to predict brain tumor grade and angiogenesis. AJNR Am J Neuroradiol 25(9):1524-1532

91. Artemov D, Solaiyappan M, Bhujwalla ZM (2001) Magnetic resonance pharmacoangiography to detect and predict chemotherapy delivery to solid tumors. Cancer Res 61:3039-3044

92. Badruddoja MA, Krouwer HG, Rand SD, Rebro KJ, Pathak AP, Schmainda KM (2003) Antiangiogenic effects of dexamethasone in 9L gliosarcoma assessed by MRI cerebral blood volume maps. Neuro-oncol 5(4):235-243.

93. Pathak A, Schmainda K, Ward B, Linderman J, Rebro KJ, Greene AS (2001) MRderived cerebral blood volume maps: issues regarding histological validation and assessment of tumor angiogenesis. Magn Reson Med 46(4):735-747.

94. Schwarzbauer C, Syha J, Haase A (1993) Quantification of regional cerebral blood volumes by rapid T1 mapping. Magn Reson Med 29:709-712.

95. Brasch R, Pham C, Shames D et al (1997) Assessing tumor angiogenesis using macromolecular MR imaging contrast media. J Magn Reson Imaging 7:68-74.

96. Patlak CS, Blasberg RG, Fenstermacher JD (1983) Graphical evaluation of blood-tobrain transfer constants from multiple-time uptake data. J Cereb Blood Flow Metab $3: 1-7$

97. Donahue KM, Weisskoff RM, Burstein D (1997) Water diffusion and exchange as they influence contrast enhancement. J Magn Reson Imaging 7(1):102-110. 
98. Kim YR, Rebro KJ, Schmainda KM (2002) Water exchange and inflow affect the accuracy of T1-GRE blood volume measurements: implications for the evaluation of tumor angiogenesis. Magn Reson Med 47(6):1110-1120.

99. Gossmann A, Helbich TH, Kuriyama N, Ostrowitzki S, Roberts TP, Shames DM, van Bruggen N, Wendland MF, Israel MA, Brasch RC (2002) Dynamic contrastenhanced magnetic resonance imaging as a surrogate marker of tumor response to anti-angiogenic therapy in a xenograft model of glioblastoma multiforme. J Magn Reson Imaging 15(3):233-240.

100. Bhujwalla ZM, Artemov D, Natarajan K, Kristjansen (2001) PEG Anti-angiogenic agent TNP-470 significantly decreases permeable regions. in 9th annual meeting, International society of magnetic resonance in medicine, Glasgow, Scotland

101. Bhujwalla ZM, Artemov D, Natarajan K, Ackerstaff E, Solaiyappan M (2001) Vascular differences detected by mri for metastatic versus nonmetastatic breast and prostate cancer xenografts. Neoplasia 3(2):143-153.

102. Artemov D (2003) Molecular magnetic resonance imaging with targeted contrast agents. J Cell Biochem 90(3):518-524.

103. Winter PM, Caruthers SD, Kassner A, Harris TD, Chinen LK, Allen JS, Lacy EK, Zhang H, Robertson JD, Wickline SA, Lanza GM (2003) Molecular imaging of angiogenesis in nascent $\mathrm{Vx}-2$ rabbit tumors using a novel alpha(nu)beta3-targeted nanoparticle and 1.5 tesla magnetic resonance imaging. Cancer Res 63(18):58385843

104. Morawski AM, Lanza GA, Wickline SA (2005) Targeted contrast agents for magnetic resonance imaging and ultrasound. Curr Opin Biotechnol 16(1):89-92.

105. Kang HW, Josephson L, Petrovsky A, Weissleder R, Bogdanov A Jr (2002) Magnetic resonance imaging of inducible E-selectin expression in human endothelial cell culture. Bioconjug Chem 13(1):122-127.

106. Sipkins DA, Cheresh DA, Kazemi MR, Nevin LM, Bednarski MD, Li KCP (1998) Detection of tumor angiogenesis in vivo by AB-targeted magnetic resonance imaging. Nat Med 4(5):623-626.

107. Sipkins DA, Gijbels K, Tropper FD, Bednarski M, Li KC, Steinman L (2000) ICAM-1 expression in autoimmune encephalitis visualized using magnetic resonance imaging. J Neuroimmunol 104(1):1-9. 
108. Yu X, Song SK, Chen J, Scott MJ, Fuhrhop RJ, Hall CS, Gaffney PJ, Wickline SA, Lanza GM (2000) High-resolution MRI characterization of human thrombus using a novel fibrin-targeted paramagnetic nanoparticle contrast agent. Magn Reson Med 44(6):867-872. doi:10.1002/1522-2594(200012)44:6<867::AID-MRM7>3.0.CO;2$\mathrm{P}$

109. Schirner M, Menrad A, Stephens A, Frenzel T, Hauff P, Licha K (2004) Molecular imaging of tumor angiogenesis. Ann N Y Acad Sci 1014:67-75.

110. Santimaria M, Moscatelli G, Viale GL, Giovannoni L, Neri G, Viti F, Leprini A, Borsi L, Castellani P, Zardi L, Neri D, Riva P (2003) Immunoscintigraphic detection of the ED-B domain of fibronectin, a marker of angiogenesis, in patients with cancer. Clin Cancer Res 9(2):571-579

111. Leong-Poi H, Christiansen J, Klibanov AL, Kaul S, Lindner JR (2003) Noninvasive assessment of angiogenesis by ultrasound and microbubbles targeted to alpha(v)integrins. Circulation 107(3):455-460.

112. Fleischer AC, Donnelly EF, Grippo RJ, Black AS, Hallahan DE (2004) Quantification of tumor vascularity with contrast-enhanced sonography: correlation with magnetic resonance imaging and fluorodeoxyglucose autoradiography in an implanted tumor. J Ultrasound Med 23(1):37-41

113. Cuccia DJ, Bevilacqua F, Durkin AJ, Merritt S, Tromberg BJ, Gulsen G, Yu H, Wang J, Nalcioglu O (2003) In vivo quantification of optical contrast agent dynamics in rat tumors by use of diffuse optical spectroscopy with magnetic resonance imaging coregistration. Appl Opt 42(16):2940-2950.

114. Padera TP, Stoll BR, So PT, Jain RK (2002) Conventional and high-speed intravital multiphoton laser scanning microscopy of microvasculature, lymphatics, and leukocyte-endothelial interactions. Mol Imaging 1(1):9-15.

115. Brown E, McKee T, diTomaso E, Pluen A, Seed B, Boucher Y, Jain RK (2003) Dynamic imaging of collagen and its modulation in tumors in vivo using secondharmonic generation. Nat Med 9(6):796-800.

116. Campagnola PJ, Millard AC, Terasaki M, Hoppe PE, Malone CJ, Mohler WA (2002) Three-dimensional high-resolution second-harmonic generation imaging of endogenous structural proteins in biological tissues. Biophys J 82(1 Pt 1):493-508

117. Dafni H, Gilead A, Nevo N, Eilam R, Harmelin A, Neeman M (2003) Modulation of the pharmacokinetics of macromolecular contrast material by avidin chase: MRI, 
optical, and inductively coupled plasma mass spectrometry tracking of triply labeled albumin. Magn Reson Med 50(5):904-914.

118. Jain RK, Munn LL, Fukumura D (2002) Dissecting tumour pathophysiology using intravital microscopy. Nat Rev Cancer 2(4):266-276.

119. Ferrari M (2005) Cancer nanotechnology: opportunities and challenges. Nat Rev Cancer 5(3):161-171.

120. Weissleder R (2002) Scaling down imaging: molecular mapping of cancer in mice. Nat Rev Cancer 2(1):11-18.

121. Smith JD, Fisher GW, Waggoner AS, Campbell PG (2007) The use of quantum dots for analysis of chick CAM vasculature. Microvasc Res 73(2):75-83.

122. Stroh M, Zimmer JP, Duda DG, Levchenko TS, Cohen KS, Brown EB, Scadden DT, Torchilin VP, Bawendi MG, Fukumura D, Jain RK (2005) Quantum dots spectrally distinguish multiple species within the tumor milieu in vivo. Nat Med 11(6):678-682.

123. Batchelor TT, Sorensen AG, di Tomaso E, Zhang WT, Duda DG, Cohen KS, Kozak KR, Cahill DP, Chen PJ, Zhu M, Ancukiewicz M, Mrugala MM, Plotkin S, Drappatz J, Louis DN, Ivy P, Scadden DT, Benner T, Loeffler JS, Wen PY, Jain RK (2007) AZD2171, a pan-VEGF receptor tyrosine kinase inhibitor, normalizes tumor vasculature and alleviates edema in glioblastoma patients. Cancer Cell 11(1):83-95.

124. Pasqualini R, Arap W, McDonald DM (2002) Probing the structural and molecular diversity of tumor vasculature. Trends Mol Med 8(12):563-571.

125. Arap W, Kolonin MG, Trepel M, Lahdenranta J, Cardo-Vila M, Giordano RJ, Mintz PJ, Ardelt PU, Yao VJ, Vidal CI, Chen L, Flamm A, Valtanen H, Weavind LM, Hicks ME, Pollock RE, Botz GH, Bucana CD, Koivunen E, Cahill D, Troncoso P, Baggerly KA, Pentz RD, Do KA, Logothetis CJ, Pasqualini R (2002) Steps toward mapping the human vasculature by phage display. Nat Med 8(2):121-127.

126. Pasqualini R, Ruoslahti E (1996) Organ targeting in vivo using phage display peptide libraries. Nature 380(6572):364-366.

127. Arap W, Pasqualini R, Ruoslahti E (1998) Cancer treatment by targeted drug delivery to tumor vasculature in a mouse model. Science 279(5349):377-380. 
128. Joyce JA, Laakkonen P, Bernasconi M, Bergers G, Ruoslahti E, Hanahan D (2003) Stage-specific vascular markers revealed by phage display in a mouse model of pancreatic islet tumorigenesis. Cancer Cell 4(5):393-403.

129. Segal E, Friedman N, Kaminski N, Regev A, Koller D (2005) From signatures to models: understanding cancer using microarrays. Nat Genet 37(Suppl):S38-S45.

130. West M, Ginsburg GS, Huang AT, Nevins JR (2006) Embracing the complexity of genomic data for personalized medicine. Genome Res 16(5):559-566.

131. Lamb J (2007) The connectivity map: a new tool for biomedical research. Nat Rev Cancer 7(1):54-60.

132. Yang JC, Haworth L, Sherry RM, Hwu P, Schwartzentruber DJ, Topalian SL, Steinberg SM, Chen HX, Rosenberg SA (2003) A randomized trial of bevacizumab, an anti-vascular endothelial growth factor antibody, for metastatic renal cancer. $\mathrm{N}$ Engl J Med 349(5):427-434.

133. Rugo HS (2004) Bevacizumab in the treatment of breast cancer: rationale and current data. Oncologist 9(Suppl 1):43-49.

134. Khurana R, Simons M (2003) Endothelial progenitor cells: precursors for angiogenesis. Semin Thorac Cardiovasc Surg 15(3):250-258. 